\title{
Postoperative Rehabilitation and Return to Sport Following Multiligament Knee Reconstruction
}

\author{
Jill Monson, P.T., O.C.S., Jon Schoenecker, P.T., O.C.S., Nicole Schwery, M.S., C.S.C.S., \\ Jamie Palmer, P.T., S.C.S., Ariel Rodriguez, M.S., and Robert F. LaPrade, M.D., Ph.D.
}

\begin{abstract}
Multiligament knee injuries (MLKIs) are debilitating injuries that increasingly occur in young athletes. Return to sport (RTS) has historically been considered unlikely due to the severity of these injuries. Reporting in the literature regarding objective outcomes following MLKI, including RTS, is lacking, as are clear protocols for both rehabilitation progressions and RTS testing. RTS following MLKI is a complex process that requires an extended recovery duration compared to other surgery types. Progressions through postoperative rehabilitation and RTS should be thoughtful, gradual, and criterion based. After effective anatomic reconstruction to restore joint stability, objective measures of recovery including range of motion, strength, movement quality, power, and overall conditioning guide decision-making throughout the recovery process. It is important to frame the recovery process of the athlete in the context of the severity of their injury, as it is typically slower and less linear. Improved reporting on objective outcomes will enhance our understanding of recovery expectations within this population by highlighting persistent deficits that may interfere with a full recovery, including RTS.
\end{abstract}

M ultiligament knee injuries (MLKIs) are defined as a tear of 2 or more of the major knee ligaments, which include the anterior cruciate ligament (ACL), posterior cruciate ligament (PCL), medial collateral ligament (MCL), and lateral collateral ligament or fibular collateral ligament (FCL). ${ }^{1,2}$ These devastating injuries are relatively uncommon, with more recent reports of 0.072 events per 100-patient years within the general population. ${ }^{1,3,4}$ MLKIs are often associated with knee dislocation, defined as a rupture of both cruciates with or without additional grade III injury to one of the collaterals. ${ }^{5}$ Disruption of the popliteal artery and/or

From Twin Cities Orthopedics (J.M., J.S.) and Training HAUS (J.M., J.S., N.S.), Eagan; and Twin Cities Orthopedics, Edina (J.P., A.R., R.F.L.), Minnesota, U.S.A.

The authors report the following potential conflicts of interest or sources of funding: R.F.L. reports grants and other from Ossur and Smith $\theta$ Nephew, and other from Linvatec and Arthrex, outside the submitted work. Full ICMJE author disclosure forms are available for this article online, as supplementary material.

Received August 3, 2021; accepted August 30, 2021.

Address correspondence to Jill Monson, P.T., O.C.S., Lead Physical Therapist - Complex Knee Injury Clinic, Twin Cities Orthopedics - Eagan, 2700

Vikings Circle,Eagan, MN 55121.E-mail: jillmonson@tcomn.com

(C) 2021 The Authors. Published by Elsevier on behalf of the Arthroscopy Association of North America. This is an open access article under the CC BYNC-ND license (http://creativecommons.org/licenses/by-nc-nd/4.0/).

2666-061X/211119

https://doi.org/10.1016/j.asmr.2021.08.020 common peroneal nerve (CPN) constitutes a medical emergency that can have devastating consequences if unrecognized. ${ }^{6}$ MLKIs are seen more commonly in younger patients, with a mean age of $37 \pm 15$ years. ${ }^{7,8}$ The incidence of knee dislocation has been inversely correlated with age. ${ }^{7,8}$ MLKIs are often associated with high-energy trauma such as a motor vehicle accidents or fall from a height; however, nearly $50 \%$, occur through a low-velocity mechanism, most commonly sport. ${ }^{9,10}$ Rates of MLKI caused by skiing sports and ball sports are as high as $29.4 \%$ and $6.9 \%$, respectively. In the same cohort, motor vehicle accidents only accounted for $19.2 \%$ of all injuries. ${ }^{7}$

Given the severity of MLKI and the complexity of multiligament knee reconstruction (MLKR), return to sport (RTS) has historically been considered highly unlikely. RTS data have been inconsistent and incomplete, but existing evidence cites a RTS rate of $53 \%,{ }^{11}$ with competitive athletes having a lower RTS rate of $22 \% .{ }^{11}$ While surgical proficiency with MLKR has improved, RTS may be hindered by concerns regarding long-term joint health. MLKI patients show high rates of concomitant injury to articular cartilage $(28.3 \%$ $48 \%)$ and menisci $(37.3 \%-55 \%)$ at the time of initial injury and a high prevalence of radiographic osteoarthritis (OA) $(23 \%-87 \%)$ following the injury. ${ }^{9,12-15}$ Poorer outcomes have been linked to meniscal pathology, cartilage pathology, and CPN palsy. ${ }^{16-18}$ 


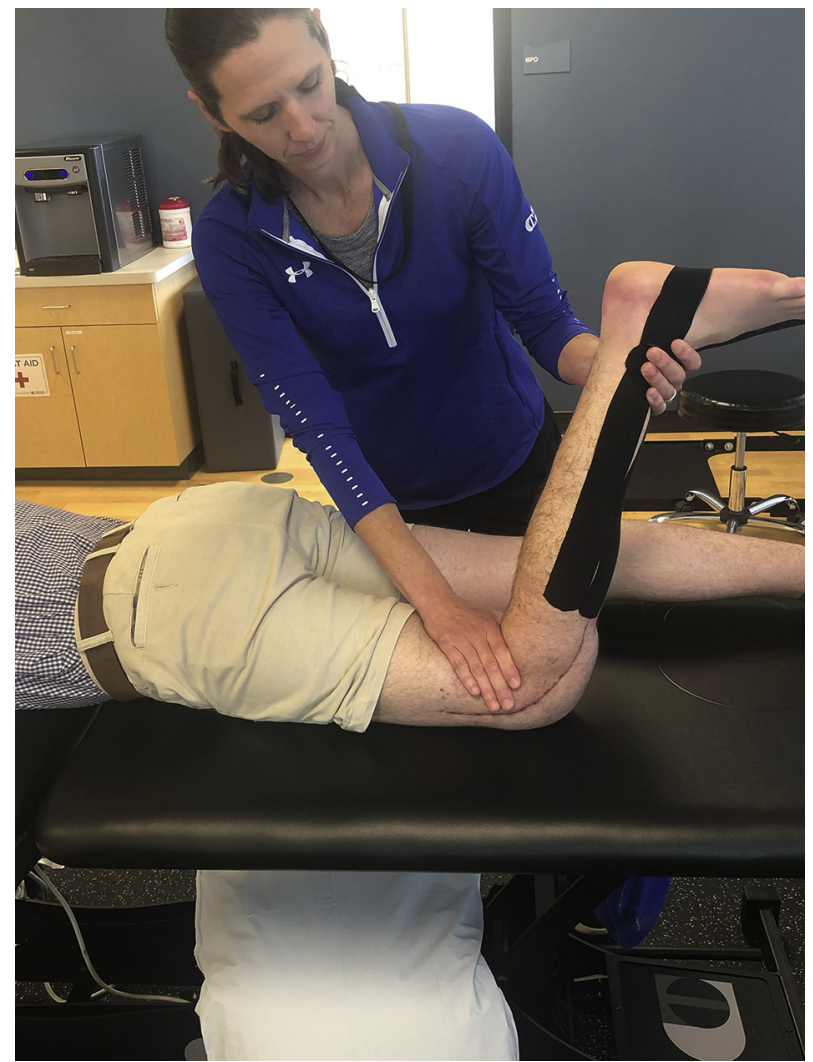

Fig 1. Prone passive range of motion.

Objective measures such as strength, balance, and power or laboratory-based reporting on functional movement patterns (squatting, hopping) are rarely reported within this population. These measures often form the central criteria for RTS decisions, as seen in the more common knee injury scenario of ACL rupture. ${ }^{19}$ The few studies investigating functional movement patterns following MLKI focus on gait. Only one study reports on quadriceps muscle strength. ${ }^{20}$ Such measures are the pillars of healthy human movement and athletic function and are ill-defined in the existing MLKI literature, which makes it difficult to interpret reported outcomes such as the progression of knee OA or rates of RTS. Given the reported links between OA progression and quadriceps muscle weakness ${ }^{21}$ we cannot isolate MLKR as a singular causative factor for OA, but rather it is likely part of a spectrum of contributing factors which may include persistent muscular weakness and faulty movement patterns.

Effective early rehabilitation followed by appropriate progressions in both exercise program design and intensity are required for RTS, yet such rehabilitation guidelines specific to MLKI are sparse within the literature. $^{22,23}$ In addition, specific guidelines for RTS within this population have not been defined with associated objective criteria. The purpose of this text is as follows: (1) define the rehabilitation process following MLKR, with an emphasis on end-stage rehabilitation and RTS progressions; (2) define objective criteria, including descriptions of performance testing protocols, used to guide progressions through each phase of therapy, including re-entry into higherlevel training and sport; and (3) describe current reported functional patient outcomes in more detail, including RTS, defining gaps in the literature, and areas for future research.

\section{Postoperative Rehabilitation}

\section{Phase 1: "Recovery" (0-8 Weeks Postoperatively)}

Initiation of rehabilitation on day 1 following surgical reconstruction has been reported to be safe and improves postoperative outcomes. ${ }^{24}$ The primary goals in this earliest stage are limb protection (bracing and crutches), symptom management, protected range of motion (ROM), quadriceps muscle activation, and return to general wellness baseline (sleep, mood, energy, and nutrition). In addition, the clinician must monitor the patient closely for postoperative complications including arthrofibrosis, nerve injury (particularly the CPN), ${ }^{18,25-27}$ deep-vein thrombosis, or signs of occult vascular injury. ${ }^{28-31}$

Cryocompressive therapy, elevation, manual lymphatic drainage, and compression garments may all be used to manage postoperative pain, joint effusion, and generalized limb edema. ${ }^{32-34}$ Non-weightbearing is enforced for the first 6 weeks with gait with a knee immobilizer worn to protect the knee. Patients who undergo posterior cruciate ligament reconstruction (PCLR) transition into a dynamic PCL brace once swelling has sufficiently resolved to minimize posterior tibial translation (PTT) forces. Patients with other ligament reconstruction transition into a hinged brace once weight-bearing resumes.

Immediate joint ROM is safe ${ }^{24}$ and crucial to reduce the risk of arthrofibrosis. ${ }^{35,36}$ Flexion is limited to $90^{\circ}$ for the first 2 weeks to protect healing grafts. Passive ROM is recommended initially after PCLR, FCL reconstruction, or biceps femoris tendon repair to minimize PTT forces on the healing PCL grafts, reduce tension at the fibular head (where tunnel drilling and distal graft anchor occurs for FCL reconstruction), or to avoid direct pulling through the repaired biceps femoris tendon, respectively. ${ }^{37,38}$ ROM is performed in prone for the first 2 weeks after PCLR, also to reduce PTT due to tibial sag related to supine positioning (Fig 1). Stretching into knee hyperextension is initially discouraged following reconstruction of the PCL, FCL, or posterolateral corner (PLC) reconstruction to limit tension on grafts of structures that natively resist knee hyperextension. ${ }^{39}$ It is critical, however, to restore full knee extension ROM. ${ }^{40-42}$ Patellofemoral mobilizations are encouraged along with frequent quadriceps muscle contractions to limit the development of excessive 
Table 1. Therapy Activity Progression Guidelines

\begin{tabular}{|c|c|c|c|c|}
\hline Exercise Task & $\begin{array}{l}\text { Minimum } \\
\text { Time to Begin }\end{array}$ & Knee ROM Goals & Strength Goals & Ability Goals \\
\hline $\begin{array}{l}\text { Cycle with no resistance (with } \\
\text { resistance) }\end{array}$ & $6 \mathrm{wk}(10 \mathrm{wk})$ & $\begin{array}{l}\text { PROM extension } 0^{\circ}, \\
\text { flexion } 120^{\circ}\end{array}$ & & Able to rotate on bike \\
\hline $\begin{array}{l}\text { Basic footwork and jumping, OKC } \\
\text { Hamstring, CKC exercise } \\
<70^{\circ} \mathrm{KF}\end{array}$ & $4 \mathrm{mo}$ & AROM squat $<70^{\circ} \mathrm{KF}$ & $\begin{array}{l}>65 \% \text { quad LSI } \\
\text { and } \mathrm{PkTq} / \mathrm{BW}\end{array}$ & $25 \mathrm{SL}$ squat from $60^{\circ} \mathrm{KF}$ at $60 \mathrm{bpm}$ \\
\hline $\begin{array}{l}\text { Hopping, sprinting, cutting and } \\
\text { pivoting progressions, sport } \\
\text { specific tasks }\end{array}$ & $6 \mathrm{mo}$ & $\begin{array}{l}\text { Extension full, flexion } \\
\text { within } 5^{\circ}\end{array}$ & & $\begin{array}{l}25 \mathrm{SL} \text { squat from } 90^{\circ} \text { at } 60 \mathrm{bpm} \text {; anterior } \\
\text { Y balance within } 4 \mathrm{~cm} \text {; Stress } \\
\text { radiographs negative }\end{array}$ \\
\hline Return to unrestricted training & $9 \mathrm{mo}$ & $\begin{array}{l}\text { Extension full, flexion } \\
\text { within } 5^{\circ}\end{array}$ & $\begin{array}{l}90 \% \text { quad LSI } \\
\text { and } \mathrm{PkTq} / \mathrm{BW} \text {; }\end{array}$ & $\begin{array}{l}90 \% \text { : SLH, TH, Y balance, SLDJ; T-test } \\
\text { within norms }\end{array}$ \\
\hline
\end{tabular}

AROM, active range of motion: LSI, limb symmetry index; PkTq/BW, peak torque relative to body weight; PROM, passive range of motion; ROM, range of motion; SLDJ, single leg drop jump; SLH, single leg hop; TH, triple hop.

suprapatellar adhesions. ${ }^{43}$ Early quadriceps activation is also crucial for restoring strength and mitigating atrophy. ${ }^{43-46}$ Open-chain resistive exercises are initially limited or modified, because quadriceps activation at greater than $60^{\circ}$ knee flexion can induce PTT and less than $30^{\circ}$ can induce anterior tibial translation, which may excessively load the healing grafts. ${ }^{37,38,47}$ Neuromuscular electrical muscular stimulation is encouraged for maximizing quadriceps muscle motor unit recruitment and has been shown to improve quadriceps function and outcomes following surgery. ${ }^{44-46}$ Blood flow restriction is a valuable modality used to mitigate muscle atrophy and strength loss and is shown to be safe and effective in appropriate populations. ${ }^{48}$ By the end of this phase, patients should exhibit full knee extension and 110 to $120^{\circ}$ of knee flexion, be able to perform consecutive repetitions of straight leg raising with no extensor lag, and demonstrate good tolerance for progressive intensity with other beginning strengthening exercises. This indicates readiness for weight-bearing progression and gait training.

\section{Transition Phase: "Acclimation to Load" (8-10/12 Weeks)}

The transition phase is the link between the Recovery and Rebuild phases. This phase has 2 main goals: (1) Progress to full weight-bearing with a non-antalgic gait pattern. (2) Prepare the joint to accept load to facilitate tolerance for future strength exercise progressions in subsequent phases. Patients acclimate to walking without crutches and may initiate basic weight bearing exercises. An effusion may still be present but must be nonreactive before phase progression.

\section{Middle- and Late-Phase Rehabilitation: "Rebuild" and "Restore"}

After the athlete successfully completes the transitional phase and tolerates basic joint loading, they can proceed to the next phases of rehabilitation. The focus is now on fully resolving any remaining ROM deficits, initiating cardiovascular and work capacity training, reestablishing tolerance to joint and tissue loading, building muscle mass with progressive resistance exercise, and reintegrating the athlete into their sporting environment. Examples of therapy activity progressions can be found in Table 1 .

All athletes may have the opportunity to return to sport following MLKI; however, the level of sport will depend on previous level of function, tolerance to rehab progressions, complexity of the injury and surgery, and the presence of nerve and/or vascular involvement with their initial injury. Realistic expectations should be discussed early in the recovery process. A CPN injury can affect lower extremity muscle function and recovery is typically slow, influenced by the initial injury severity, with $87.3 \%$ of patients with partial CPN palsy reported to experience a full functional recovery compared with only $38.4 \%$ of patients with complete palsy. ${ }^{49}$ If complete palsy persists, a tendon transfer may be needed in the months following surgery to achieve some level of active dorsiflexion. Return to high-level cutting and pivoting following a tendon transfer may not be advised; however, certain sports (ie, downhill skiing) may be possible.

Individuals with a vascular injury experience worse long-term functional outcomes ${ }^{50}$ and less flexion ROM following surgery. ${ }^{51}$ The effect of a vascular disruption on ligamentous healing is unclear, but it is the author's experience that these patients have increased postoperative laxity in general on stress radiographs compared with patients without a vascular injury. Articular cartilage health may be affected by MLKI and surgery. At a median of 12.7 years following a MLKR, radiographic OA was present in $42 \%$ of operated knees compared with only $6 \%$ on the contralateral side, 9 although similar results have been seen following 
Table 2. Sport Performance Testing Details and Goals

\begin{tabular}{|c|c|c|c|}
\hline & $\begin{array}{l}\text { Baseline (4 Months } \\
\text { Postoperative) }\end{array}$ & $\begin{array}{c}\text { Follow-Up l } \\
\text { (7 Months Postoperative) }\end{array}$ & $\begin{array}{c}\text { Follow-Up } 2 \\
\text { (10+ Months Postoperative) }\end{array}$ \\
\hline $\begin{array}{l}\text { Basic clinical } \\
\text { measures }\end{array}$ & $\begin{array}{l}\text { - } \text { Knee joint ROM } \\
\text { - Ankle joint ROM } \\
\text { - } \text { Circumferential limb } \\
\text { measures-muscle girth } \\
\text { - Swelling measures } \\
\text { - Hip strength with HHD } \\
\text { (omit if s/p FCLR, PLCR) }\end{array}$ & $\begin{array}{l}\text { - } \text { Repeat baseline tests } \\
\text { - Hip strength with HHD for all } \\
\text { surgery } \\
\text { types }\end{array}$ & - Repeat baseline tests \\
\hline $\begin{array}{l}\text { Goals (for lower-extremity } \\
\text { functional testing) }\end{array}$ & $\begin{array}{l}\text { Y-balance: } \leq 8 \mathrm{~cm} \text { SSD } \\
1 \text { leg rise test (from } 60^{\circ} \mathrm{KF} \text { ) } \\
\text { @ } 60 \text { bpm: able to complete } 25 \\
\text { consecutive reps }\end{array}$ & $\begin{array}{l}\text { Y-balance: } \leq 4 \mathrm{~cm} \text { SSD } \\
\text { 1 leg rise test (from } 90^{\circ} \mathrm{KF} \text { ): } \\
\text { able to complete } 25 \text { reps } \\
\text { Hop testing: } \geq 80 \% \text { LSI }\end{array}$ & $\begin{array}{l}\text { Y-balance: } \leq 4 \mathrm{~cm} \text { SSD (Raw score } \\
\text { relative to limb length within } 10 \% \text { of } \\
\text { age/sex-matched norm values) } \\
1 \text { leg rise test (from } 90^{\circ} \mathrm{KF} \text { ): able to } \\
\text { complete } 25 \text { reps } \\
\text { Hop Testing: } \geq 90 \% \text { LSI (Raw } \\
\text { score within } 10 \% \text { of age/sex-matched } \\
\text { norm values) }\end{array}$ \\
\hline Biomechanics lab tests & $\begin{array}{l}\text { Isometric dynamometer } \\
\text { quadriceps muscle strength }\end{array}$ & $\begin{array}{l}\text { - Repeat/add: Isometric quad } \\
\text { strength, isokinetic quadriceps } \\
\text { and hamstring muscle strength } \\
\text { - Add: hop testing with motion } \\
\text { capture over force plates as } \\
\text { appropriate }\end{array}$ & $\begin{array}{l}\text { - Repeat: Isometric quad strength, } \\
\text { isokinetic testing } \\
\text { - Add/repeat: hop testing with motion } \\
\text { capture over force plates }\end{array}$ \\
\hline
\end{tabular}

BW, body weight; CKC, closed kinetic chain; DF, ankle dorsiflexion; FCLR, fibular collateral ligament reconstruction; HHD, hand-held dynamometer; KF, knee flexion; LSI, limb symmetry index; PLCR, posterolateral corner reconstruction; ROM, range of motion; SLFH, singleleg forward hop; SLHD, single-leg hop for distance; SSD, side-to-side difference; THD, triple hop for distance.

ACL rupture, as $60 \%$ to $90 \%$ of individuals will eventually present with radiographic evidence of OA. ${ }^{52}$ Higher quadriceps limb symmetry 5 years following an ACL reconstruction has recently been associated with a lower incidence of clinical knee $\mathrm{OA}^{53}$ highlighting the importance of sound rehabilitation and load progressions, especially for the quadriceps muscles within patients recovering from this more complex injury and surgery.

\section{"Rebuild" (10 Weeks-6 Months)}

At 10 weeks postsurgery, the rehabilitation emphasis changes from basic recovery from surgery to rebuilding the athlete's knee in terms of biomechanics, proprioception, and movement patterns outside of linear gait progressions. Generalized weakness and muscular atrophy are still present, most notably at the quadriceps and hamstring muscles, due to non-weight-bearing status, postoperative arthrogenic 


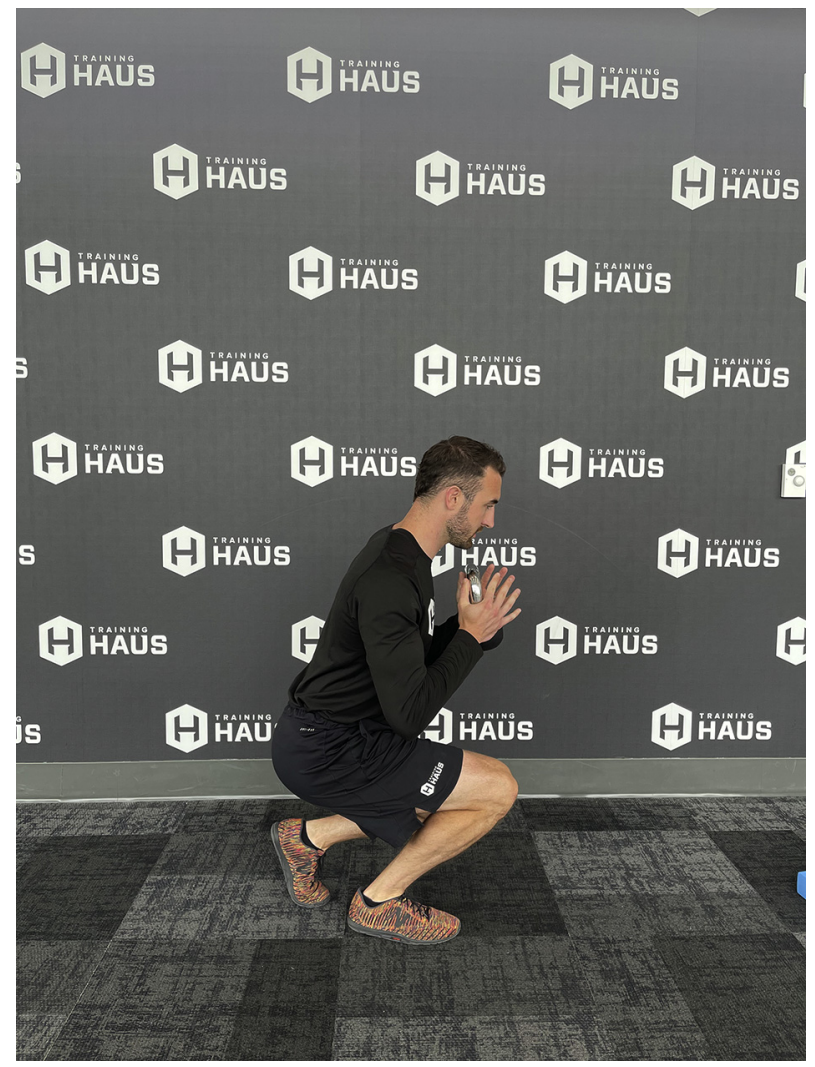

Fig 2. Knee over toes position with "kickstand" squat.

quadriceps inhibition, and the strict "hamstring-off" passive ROM precaution in the early phases. Therefore, loading progressions for regaining muscle strength and size are emphasized during this stage. Recovery goals for 4 months postoperative are listed in Table 2.

\section{Progressions}

\section{Before Four Months}

If the athlete had a PCL or PLC reconstruction, openchain hamstring strengthening is avoided. Hamstring activation beyond $30^{\circ}$ of knee flexion induces PTT, which could be detrimental to a healing PCLR or PLC, ${ }^{38}$ so strengthening from 6 weeks to 4 months involves submaximal effort exercises in shallow knee flexion angles. Open-chain quadriceps strength exercises are critical to isolate the muscle and recover strength. Closed-chain or weight-bearing quadriceps strengthening through squat, step-up, or lunge drills is initially limited to a depth of $70^{\circ}$ of knee flexion to avoid the PTT that occurs in deeper squatting angles. ${ }^{54,55}$ Squat technique should ensure adequate knee over toe mechanics (Fig 2) to maximize quadriceps muscle activation, with gradual progressions that honor joint or tendon symptoms.

\section{At Four Months}

All postoperative exercise restrictions lapse. Hamstring exercises are progressed gradually per the required muscular demand of the exercise. ${ }^{56}$ The Nordic hamstring exercise (Fig 3) is incorporated last due to the kneeling position and high levels of muscle activation, which can be contraindicated initially following PCLR. Athletes are now able to progress closed chain knee flexion loading (i.e., squatting) deeper than $70^{\circ}$. Single-leg loading is a focus of early strength training to minimize potential movement compensations, due to weakness, associated with double leg loading. Examples of closed-chain loading progressions are detailed in Table 3.

Strengthening strategies are employed at various points along the force velocity curve, beginning with loaded isometrics, which are safe and nonirritating on the joint and can elicit strength improvements ${ }^{57}$; exertion levels should progress over time. Eccentric and heavy slow resistance exercises, which include slow eccentric, isometric, and concentric phases, are incorporated next. Heavy slow resistance exercise has been shown to be beneficial for patellar tendinopathy ${ }^{58}$; it is not uncommon for athletes who have had a patellar tendon autograft to experience some level of anterior knee pain, similar to patellar tendinopathy, following

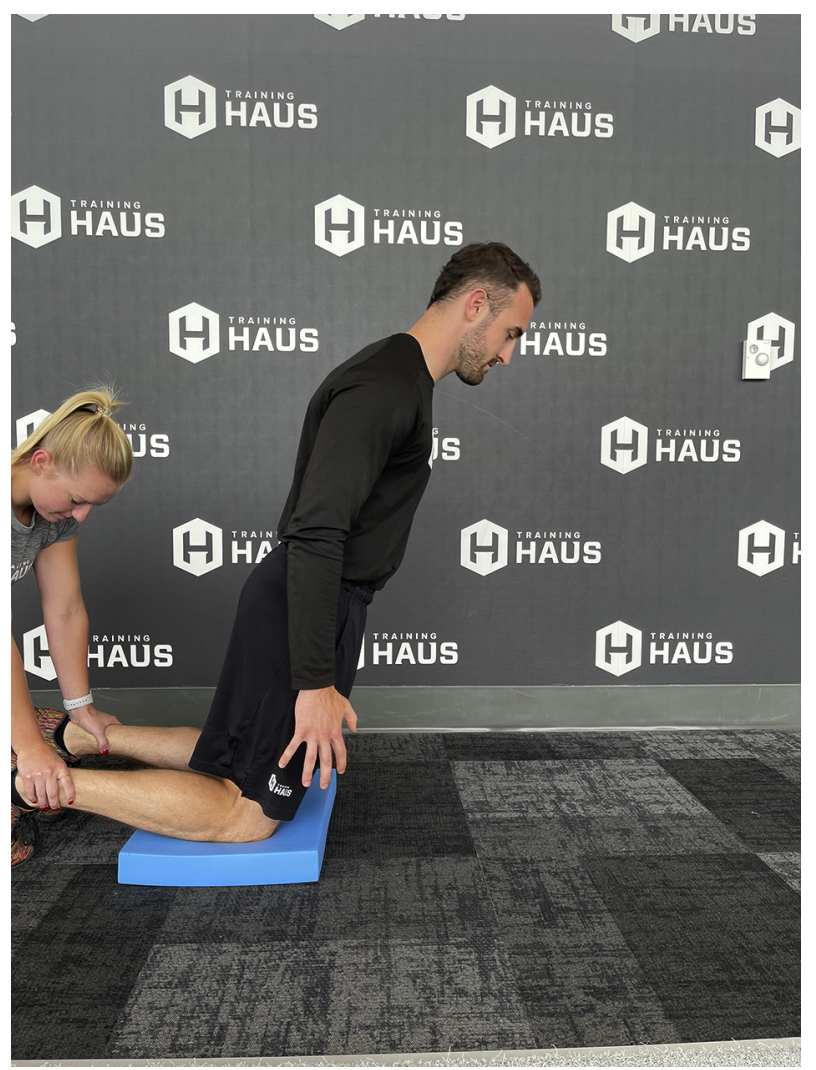

Fig 3. Nordic hamstring exercise. 
their MLKR. Blood flow restriction for the purpose of pain control can also be incorporated. ${ }^{59}$ As strength and capacity improve, speed of movement increases, beginning with the concentric component. Loaded, quick movements with a shorter amortization phase are incorporated last.

\section{Load Monitoring}

Once external loads are tolerated, the overload principle is applied by progressively increasing load over time to increase strength. ${ }^{60}$ Traditional periodization concepts are applied in early phases with greater repetition counts and lower loads, and later phases with lower reps and greater load; however, additional strategies outside the periodization framework have value. To maximize the effectiveness of each lifting session, self-monitoring parameters, commonly referred to as "autoregulation," are used. Subjective ratings of perceived exertion and repetitions in reserve following a set as well as velocity-based training methods have shown to be useful to tailor workout intensity per recovery between sets. ${ }^{61,62}$ This type of training allows for real-time load adjustments to achieve the resistance necessary to attain maximum effort. ${ }^{61,62}$ Strict adherence to a traditional preplanned periodization model may be less important ${ }^{63}$ than more precisely manipulating load to approach muscular failure within an exercise. $^{64,65}$

\section{Cardiovascular and Work Capacity Training}

Early initiation of work capacity and energy system development is vital for general activity preparedness and to gradually increase tolerance to repeated exercise bouts at a progressively greater capacity, as required for sport. Exercise sessions should progress in duration, intensity and work to rest ratios, while avoiding single session or weekly spikes in volume of work completed. ${ }^{66}$ Workout intensity can be monitored through exertion scales or other means (i.e., wearable technologies). Intensity should increase gradually for safe and successful return to pre-injury activity and conditioning levels. ${ }^{67}$

\section{Rate of Force Development}

The ability to produce maximum force is different than producing force at a high rate. Preinjury strength levels have been shown to return sooner than rate of force development (RFD) following ACL reconstruction, ${ }^{68}$ so a similar, if not greater, delay or depression in recovery of RFD is likely following MLKR. RFD training can begin as early as 4 months postoperation and can progress from higher speed "making" isometrics to quick concentric or eccentric "braking" activities using the stretch-shortening cycle. The importance of RFD, including more comprehensive training descriptions, have been described in detail elsewhere. ${ }^{69}$

\section{Sensorimotor Training}

ACL injury has been shown to alter the nervous system's ability to interpret somatosensory information, causing heavier reliance on visual feedback, so it is expected that a MLKI will have equal or more somatosensory deficits. ${ }^{70}$ Principles of motor learning are incorporated into all stages of rehabilitation to normalize nervous system functioning. An external focus of attention is a primary guiding strategy where the athlete is asked to focus on something other than their knee while performing an exercise. An external focus can expedite learning by facilitating automatic movements and thus depressing intracortical inhibition of voluntary muscle activation. ${ }^{71}$ Simple cognitive distractions like verbalizing a color or number displayed on a cell phone app, or having the athlete count backwards simultaneously with exercise, can begin early in recovery.

\section{"Restore" (6 Months to 1+ Year)}

The care plan following MLKR is typically extended, with increased time off school or work and an increased strain on resources such as insurance coverage, economics, transportation, and in-home support. ${ }^{72-74}$ The layout and duration of the Restore phase will vary, depending on the level of sport, the ability to continue with frequent rehabilitation visits, and the level of involvement of secondary providers. If an athlete is competing at the high school, collegiate, or professional level, coordination with their athletic trainer and strength coach is important as physical therapy visits taper in frequency. Small group training sessions, outside of insurance-covered therapy appointments, have become a popular option to provide supervised, higher-level training progressions in the later phases of recovery. The downside of this practice is the potential exclusion of athletes with fewer economic resources. $^{74}$

\section{Return to Run and Sprint}

A return to running progression begins once the athlete attains sufficient quadriceps strength, masters preparatory running drills, and meets performance targets with clinical testing (Table 2). Recently, Iwame et al. ${ }^{75}$ reported that those individuals who met a cutoff value for quad strength divided by body weight of 1.45 $\mathrm{Nm} / \mathrm{kg}$ had success with return to jogging, highlighting the importance of strength for normal running gait. A minimum period of 4 weeks with a jogging buildup program should be completed before the initiation of straight-line sprint progressions. ${ }^{76}$

\section{Progressions}

Transition from linear movements to change of direction tasks should begin with rounded turns, then gradually move to sharper angled cutting and greater speeds. Cognitive demands and sport-specific tasks are 
Table 3. Closed-Chain Loading Activity Progression Examples

\begin{tabular}{|c|c|c|c|}
\hline Examples of Closed-Chain Exercise Tasks & $\begin{array}{l}\text { Minimum Time } \\
\text { to Begin }\end{array}$ & $\begin{array}{c}\text { Functional } \\
\text { Prerequisites }\end{array}$ & $\begin{array}{l}\text { Sets (Surgical: Nonsurgical), } \\
\text { Reps (Surgical: Nonsurgical), } \\
\text { Hold Time }\end{array}$ \\
\hline Forward lunge ISO hold over a step & $8 w k$ & $\begin{array}{l}30 \text { reps straight leg raise with } \\
\text { no lag }\end{array}$ & $\begin{array}{l}1-2(1: 1), 2-10(1: 1), 5-30 \\
\text { second isometric }\end{array}$ \\
\hline $\begin{array}{l}\text { Single-leg kickstand (Fig 2) or split squat with } \\
\text { body weight }\end{array}$ & $10 \mathrm{wk}$ & $\begin{array}{l}\text { Athlete feels muscle activation } \\
\text { more than knee irritation }\end{array}$ & $1-2(1: 1), 2-10(1: 1), 5-30$ seconds \\
\hline $\begin{array}{l}\text { Single-leg kickstand squat with dumbbell or } \\
\text { kettlebell external load }\end{array}$ & $12 \mathrm{wk}$ & $\begin{array}{l}\text { Athlete feels muscle activation } \\
\text { more than knee irritation }\end{array}$ & $\begin{array}{l}2(1: 1), 12(1: 1), 2-30 \text { second phases } \\
\text { eccentric/isometric/concentric }\end{array}$ \\
\hline $\begin{array}{l}\text { Single-leg kickstand squat with Hex/safety/barbell } \\
\text { straight bar external load }\end{array}$ & $5 \mathrm{mo}$ & $75 \%$ quad LSI & $\begin{array}{l}2-4(4: 2), 12(1: 1), 2-6 \text { second phases } \\
\text { eccentric/isometric/concentric }\end{array}$ \\
\hline Single and double leg loading & $7 \mathrm{mo}$ & & $3-5(5: 2), 4-8(1-2: 1), 0-3$ seconds \\
\hline Single- and double-leg loading & $9 \mathrm{mo}$ & $90 \%$ quad LSI and $\mathrm{PkTq} / \mathrm{BW}$ & $3-5(5: 2), 2-5(1-2: 1), 0-3$ seconds \\
\hline
\end{tabular}

ISO, isolmetric; LSI, limb symmetry index; PkTq/BW, peak torque relative to body weight.

incorporated per readiness. The "control-chaos continuum," as described by Taberner et al., ${ }^{77}$ progresses the athlete from slow, controlled preplanned movements to fast, chaotic reactive sport-specific movements in the "on-field" environment. As the athlete moves through the Restore phase, they should see an increasing volume of load, skill, and physical fitness training while alternating difficult days with easier days to allow for recovery. ${ }^{78}$ If an athlete returns to sport without having the capacity to do so, they are at a greater risk of injury. ${ }^{79}$ As such, sport-specific training and within-sport participation is incorporated on a gradual continuum.

\section{Testing for RTS}

While there is no solid agreement on the best RTS criteria, a battery of tests including objective strength testing, single-leg hop testing and validated subjective questionnaires is advocated to assess overall readiness. ${ }^{80,81}$ Our MLKI RTS testing protocol (Table 2) mimics those used within the ACL population, as protocols specific to MLKI have yet to be defined or validated. Testing at our center is performed at 4, 7, and 10 months after surgery. Typical RTS testing time points are at 3, 6, 9 months, ${ }^{82-84}$ but the increased trauma and restrictions during early rehabilitation in this population warrants testing at later time points.

\section{Strength Testing}

Measurement of muscle function, specifically isolated quadriceps performance, can reveal deficits otherwise disguised though compensation strategies within functional movement testing. Our center tests both isometric and isokinetic strength using an isokinetic dynamometer. Quadriceps isometric strength is evaluated at $90^{\circ}$ of knee flexion (Fig 4) at each time interval, while isokinetic quadriceps and hamstrings strength is evaluated at $60 \mathrm{deg} / \mathrm{s}$ at only the 7 - and 10 -month test intervals due to the hamstring precautions in early rehabilitation. A goal of $>90 \%$ limb symmetry index is recommended for both quadriceps and hamstring strength at time of RTS. ${ }^{81,85}$ Relative strength (strength compared with an athlete's body weight) has shown to be a good predictor of patientreported knee function and may be a better indicator for dynamic knee-joint stability and absorption of joint loads during activity. ${ }^{80,86} \mathrm{~A}$ goal of quadriceps isometric strength $\geq 3.0 \mathrm{Nm} / \mathrm{kg}$ is established within our MLKI RTS criteria.

\section{Lower-Extremity Functional Testing}

A number of tasks have been used to assess kinematic and kinetic compensation strategies in athletes after injury, such as double-leg squat, single-leg squat (SLS), double-leg jump, and single-leg forward hop

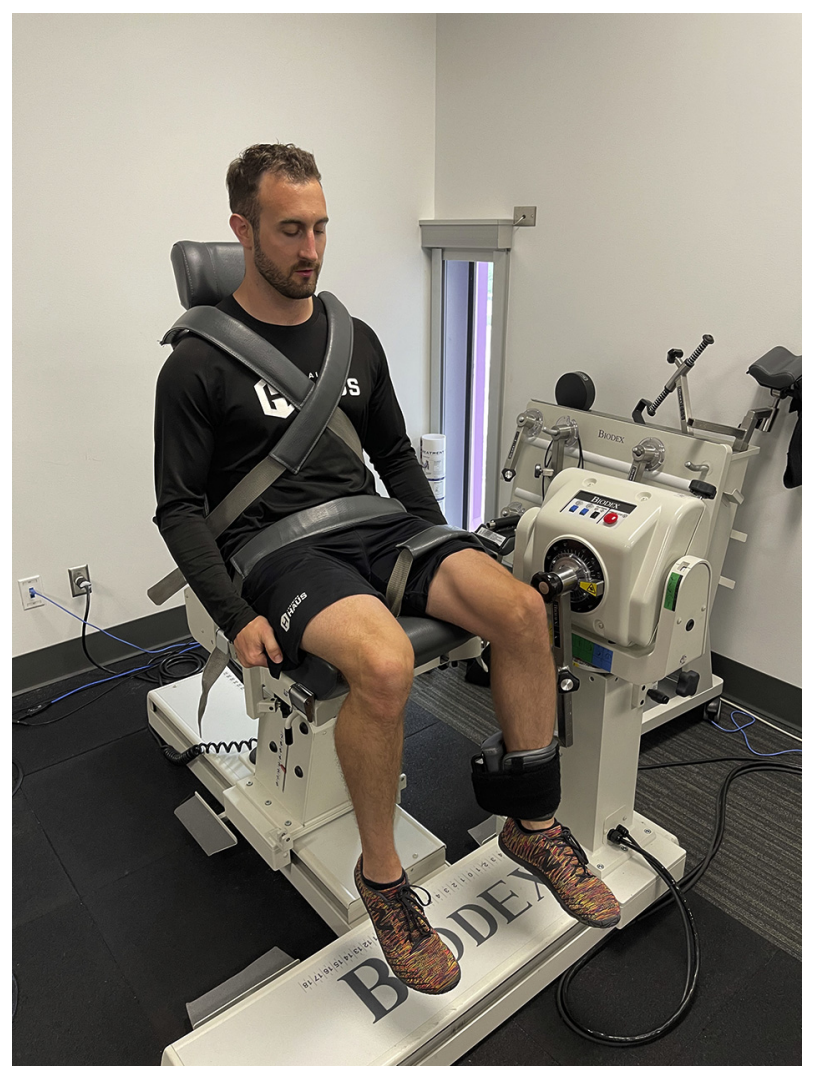

Fig 4. Quadriceps strength testing on an isokinetic dynamometer. 


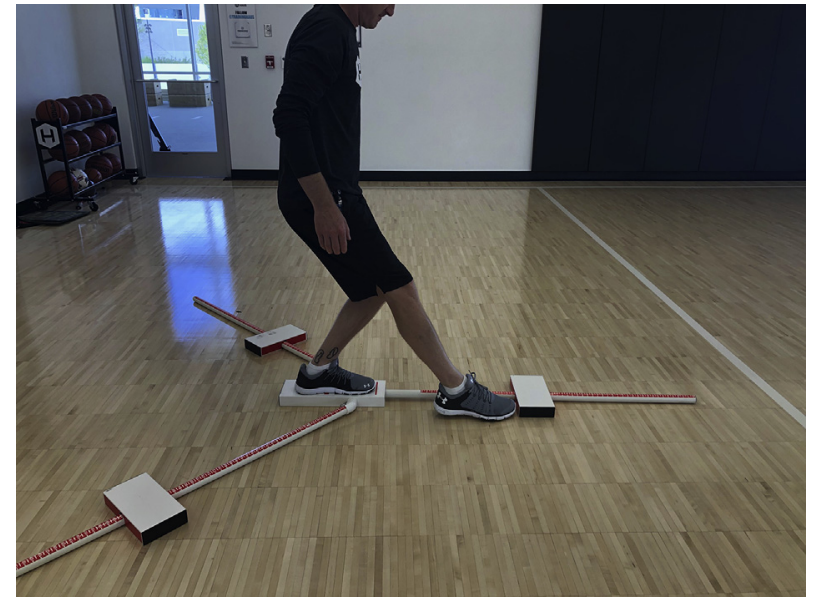

Fig 5. Y-balance squat test - anterior reach.

(SLFH). ${ }^{80,85,87,88}$ Specifically, altered landing mechanics have been shown to be an important predictor of ACL reinjury. ${ }^{89-91}$ Therefore, examining these same mechanics within the MLKI population is of interest. The goal for MLKI athletes is to exhibit less than a $10 \%$ deficit in SLFH distance and peak knee flexion during both SLS and SLFH landings. In addition, the surgical limb should achieve deep knee flexion, defined as $>75^{\circ}$, during peak knee flexion in SLS and SLFH landings. Asymmetrical limb-loading and decreased functional knee stability have been shown to be associated with quadriceps weakness and likeliness to RTS $^{92,93}$; therefore, it is important for MLKI individuals to restore excellent limb symmetry when returning to activities.

\section{Subjective Testing}

Subjective patient-reported outcome measures (PROMs) have become increasingly popular in predicting RTS. $^{86,94}$ The Knee injury Osteoarthritis Outcome Score, International Knee Documentation Committee 2000 Subjective Knee Form, and the ACLReturn to Sport after Injury are traditional PROMs consistently reported in ACL literature and have shown to be strongly associated with RTS objective measures. ${ }^{90,95-97}$ The ACL-Return to Sport after Injury , validated within the ACL population, includes questions regarding emotional well-being, physical performance confidence, and appraisal of risk. According to Sadeqi et al., ${ }^{95}$ those who score $\geq 60$ at 6 months postsurgery will likely return to the preinjury level at 2 years after surgery. Greater confidence in performance combined with less fear have been shown to distinguish those who do and do not RTS. ${ }^{96,98}$ No PROMs have been validated in the MLKI population. Studies including Knee injury Osteoarthritis Outcome Score and International Knee Documentation Committee 2000 Subjective Knee Form outcomes often report on data collected years after surgery and are not specific to RTS. ${ }^{99,100}$

\section{RTS: Clinician Guidelines and Reported Outcomes}

This step will look different for each athlete depending on their surgery, previous level of function, and goals. ACL reconstruction literature has shown that returning to sport before 9 months may lead to a greater rate of reinjury. ${ }^{82,101}$ Similar research regarding recommended RTS timelines does not exist specific to MLKR. At our center, athletes are educated that return to play will likely take 12 to 18 months. Managing expectations is important in this population, given poor existing reports on RTS $53 \%$ of patients with MLKR return to any level of sport, and $22 \%$ return to highlevel sport). ${ }^{11}$ The specific ligaments involved may make a difference as well. Fifty athletes from the National Football League were observed following MLKR to find that $70.8 \%$ of ACL/MCL tears and $55.6 \%$ of ACL with PCL or FCL involvement returned to play at $305.1 \pm 58.9$ and $459.2 \pm 245.1$ days, respectively. Return to previous performance was $43.5 \%$ for ACL/ MCL and $18.5 \%$ for ACL with PCL or FCL. In comparison, a case series of 165 National Football League athletes reported an $82.4 \%$ return to play rate when undergoing an isolated ACL reconstruction. ${ }^{102}$

The majority of MLKI literature agrees that fear of reinjury was the biggest contributor to not returning to competitive sports. ${ }^{103}$ A variety of clinical and laboratory objective tests are essential for safe return to play decision-making, ${ }^{39}$ and MLKI research lacks both foundational objective measures and population specific validated PROMs. Only one study was found that measured strength, reporting $84 \%$ quadriceps and $90 \%$ hamstring limb symmetry indices at 24 months postoperatively. ${ }^{20}$ These quadriceps strength outcomes at 2 years postoperatively are substandard and raise concern, as most athletes seek to return to sport within 12 months from surgery. To our knowledge, no study has examined jumping or hopping performance following MLKR. Only gait analyses have been conducted, however, often years after surgery. MLKI patients exhibited slower gait, shorter steps, and altered knee kinematics compared with healthy controls. ${ }^{104-107}$ Our RTS testing protocol, including goal values, is illustrated in Table 2.

\section{Conclusions}

MLKIs can be debilitating for athletes. Historically, return to play after a MLKI has been out of the question; however, with the advancement of surgical proficiency using an anatomic reconstruction, the prognosis for recovery following MLKI has changed. ${ }^{24}$ With the initiation of rehabilitation on day 1 after surgery, effective progressions through a 
comprehensive rehabilitation process, and realistic expectations regarding timelines, RTS is possible. It is important to consider the extent of the injury to set appropriate expectations for recovery and RTS. Objective outcomes reporting and guidelines for rehabilitation progressions to return an athlete to sport following MLKR are lacking. RTS testing following MLKR should be criterion based and use a combination of strength, functional, and subjective testing. The rehabilitation process following MLKR is typically slower overall, and RTS phases will be longer. The process can be physically and mentally taxing for the patient and practitioner; however, by following a conservative approach with deliberately cautious phase progressions a successful, safe return to sport is possible.

\section{References}

1. Levy BA, Dajani KA, Whelan DB, et al. Decision making in the multiligament-injured knee: An evidence-based systematic review. Arthroscopy 2009;25:430-438.

2. Wascher DC, Dvirnak PC, DeCoster TA. Knee dislocation: Initial assessment and implications for treatment. J Orthop Trauma 1997;1 1:525-529.

3. Kennedy JC. Complete dislocation of the knee joint. J Bone Joint Surg Am 1963;45:889-904.

4. Arom GA, Yeranosian MG, Petrigliano FA, Terrell RD, McAllister DR. The changing demographics of knee dislocation: A retrospective database review. Clin Orthop Relat Res 2014;472:2609-2614.

5. Schenck R. Classification of knee dislocations. Oper Tech Sports Med 2003;11:193-198.

6. Medina O, Arom GA, Yeranosian MG, Petrigliano FA, McAllister DR. Vascular and nerve injury after knee dislocation: A systematic review. Clin Orthop Relat Res 2014;472:2621-2629.

7. Moatshe G, Dornan GJ, Løken S, Ludvigsen TC, LaPrade RF, Engebretsen L. Demographics and injuries associated with knee dislocation: A prospective review of 303 patients. Orthop J Sports Med 2017;5: 2325967117706521.

8. Schlumberger M, Schuster P, Eichinger M, Mayer P, Mayr R, Immendörfer M, et al. Posterior cruciate ligament lesions are mainly present as combined lesions even in sports injuries. Knee Surg Sports Traumatol Arthrosc 2020;28:2091-2098.

9. Moatshe G, Dornan GJ, Ludvigsen T, Løken S, LaPrade RF, Engebretsen L. High prevalence of knee osteoarthritis at a minimum 10-year follow-up after knee dislocation surgery. Knee Surg Sports Traumatol Arthrosc 2017;25:3914-3922.

10. Janousek AT, Jones DG, Clatworthy M, Higgins LD, Fu FH. Posterior cruciate ligament injuries of the knee joint. Sports Med 1999;28:429-441.

11. Everhart JS, Du A, Chalasani R, Kirven JC, Magnussen RA, Flanigan DC. Return to work or sport after multiligament knee injury: A systematic review of 21 studies and 524 patients. Arthroscopy 2018;34: 1708-1716.
12. Krych AJ, Sousa PL, King AH, Engasser WM, Stuart MJ, Levy BA. Meniscal tears and articular cartilage damage in the dislocated knee. Knee Surg Sports Traumatol Arthrosc 2015;23:3019-3025.

13. Engebretsen L, Risberg MA, Robertson B, Ludvigsen TC, Johansen S. Outcome after knee dislocations: A 2-9 years follow-up of 85 consecutive patients. Knee Surg Sports Traumatol Arthrosc 2009;17:1013-1026.

14. Fanelli GC, Sousa PL, Edson CJ. Long-term followup of surgically treated knee dislocations: Stability restored, but arthritis is common. Clin Orthop Relat Res 2014;472: 2712-2717.

15. Hirschmann MT, Zimmermann N, Rychen T, et al. Clinical and radiological outcomes after management of traumatic knee dislocation by open single stage complete reconstruction/repair. BMC Musculoskelet Disord 2010;11: 102.

16. King AH, Krych AJ, Prince MR, Sousa PL, Stuart MJ, Levy BA. Are meniscal tears and articular cartilage injury predictive of inferior patient outcome after surgical reconstruction for the dislocated knee? Knee Surg Sports Traumatol Arthrosc 2015;23:3008-3011.

17. Mook WR, Ligh CA, Moorman CT 3rd, Leversedge FJ. Nerve injury complicating multiligament knee injury: Current concepts and treatment algorithm. J Am Acad Orthop Surg 2013;21:343-354.

18. Niall DM, Nutton RW, Keating JF. Palsy of the common peroneal nerve after traumatic dislocation of the knee. J Bone Joint Surg Br 2005;87:664-667.

19. Grindem H, Eitzen I, Moksnes H, Snyder-Mackler L, Risberg MA. A pair-matched comparison of return to pivoting sports at 1 year in anterior cruciate ligamentinjured patients after a nonoperative versus an operative treatment course. Am J Sports Med 2012;40: 2509-2516.

20. Jenkins PJ, Clifton R, Gillespie GN, Will EM, Keating JF. Strength and function recovery after multiple-ligament reconstruction of the knee. Injury 201 1;42:1426-1429.

21. Amin S, Baker K, Niu J, Clancy M, Goggins J, Guermazi A, et al. Quadriceps strength and the risk of cartilage loss and symptom progression in knee osteoarthritis. Arthritis Rheum 2009;60:189-198.

22. Medvecky MJ, Zazulak BT, Hewett TE. A multidisciplinary approach to the evaluation, reconstruction and rehabilitation of the multi-ligament injured athlete. Sports Med 2007;37:169-187.

23. Lynch SA, Renström PA. Treatment of acute lateral ankle ligament rupture in the athlete. Conservative versus surgical treatment. Sports Med 1999;27:61-71.

24. LaPrade RF, Chahla J, DePhillipo NN, Cram T, Kennedy MI, Cinque M, et al. Single-stage multipleligament knee reconstructions for sports-related injuries: Outcomes in 194 patients. Am J Sports Med 2019;47:2563-2571.

25. Krych AJ, Giuseffi SA, Kuzma SA, Stuart MJ, Levy BA. Is peroneal nerve injury associated with worse function after knee dislocation? Clin Orthop Relat Res 2014;472: 2630-2636.

26. Peskun CJ, Chahal J, Steinfeld ZY, Whelan DB. Risk factors for peroneal nerve injury and recovery in knee dislocation. Clin Orthop Relat Res 2012;470:774-778. 
27. Dy CJ, Inclan PM, Matava MJ, Mackinnon SE, Johnson JE. Current concepts review: Common peroneal nerve palsy after knee dislocations. Foot Ankle Int 2021;42:658-668.

28. Shahrulazua A, Rafedon M, Mohd Nizlan MN, Sullivan JA. Delayed compartment syndrome of leg and foot due to rupture of popliteal artery pseudoaneurysm following posterior cruciate ligament reconstruction. BMJ Case Rep 2014;2014.

29. Kwok-Wai TK, Yiu-Chung W, Chi-Yuk L, Yuk-Yin C. Pseudoaneurysm of the popliteal artery after anterior cruciate ligament reconstruction surgery: A case report and literature review. J Orthop Trauma Rehabil 2014;18: 44-46.

30. Bernhoff K, Michaëlsson K, Björck M. Incidence and outcome of popliteal artery injury associated with knee dislocations, ligamentous injuries, and close to knee fractures: A nationwide population based cohort study. Eur J Vasc Endovasc Surg 2021;61:297-304.

31. Bernhoff K, Björck M. Iatrogenic popliteal artery injury in non arthroplasty knee surgery. Bone Joint J 2015;97-b: 192-196.

32. Wou J, Williams KJ, Davies AH. Compression stockings versus neuromuscular electrical stimulation devices in the management of occupational leg swelling. Int J Angiol 2016;25:104-109.

33. Tischer TS, Oye S, Lenz R, Kreuz P, Mittelmeier W, Bader R, et al. Impact of compression stockings on leg swelling after arthroscopy-a prospective randomised pilot study. BMC Musculoskelet Disord 2019;20:161.

34. Mosti G, Picerni P, Partsch H. Compression stockings with moderate pressure are able to reduce chronic leg oedema. Phlebology 201 1;27:289-296.

35. Huleatt J, Gottschalk M, Fraser K, Boden A, Dalwadi P, Xerogeanes J, et al. Risk factors for manipulation under anesthesia and/or lysis of adhesions after anterior cruciate ligament reconstruction. Orthop J Sports Med 2018;6: 2325967118794490.

36. Marom N, Ruzbarsky JJ, Roselaar N, Marx RG. Knee MLI injuries: Common problems and solutions. Clin Sports Med 2018;37:281-291.

37. Lutz GE, Palmitier RA, An KN, Chao EY. Comparison of tibiofemoral joint forces during open-kinetic-chain and closed-kinetic-chain exercises. J Bone Joint Surg Am 1993;75:732-739.

38. Markolf KL, O’Neill G, Jackson SR, McAllister DR. Effects of applied quadriceps and hamstrings muscle loads on forces in the anterior and posterior cruciate ligaments. Am J Sports Med 2004;32:1144-1149.

39. Halewood C, Amis AA. Clinically relevant biomechanics of the knee capsule and ligaments. Knee Surg Sports Traumatol Arthrosc 2015;23:2789-2796.

40. Irrgang JJ, Harner CD. Loss of motion following knee ligament reconstruction. Sports Med 1995;19:150-159.

41. Shelbourne KD, Urch SE, Gray T, Freeman H. Loss of normal knee motion after anterior cruciate ligament reconstruction is associated with radiographic arthritic changes after surgery. Am J Sports Med 2012;40: 108-113.

42. Shelbourne KD, Gray T. Minimum 10-year results after anterior cruciate ligament reconstruction: How the loss of normal knee motion compounds other factors related to the development of osteoarthritis after surgery. Am J Sports Med 2009;37:471-480.

43. Mikula JD, Slette EL, Dahl KD, Montgomery SR, Dornan GJ, O'Brien L, et al. Intraarticular arthrofibrosis of the knee alters patellofemoral contact biomechanics. $J$ Exp Orthop 2017;4:40.

44. Hart JM, Pietrosimone B, Hertel J, Ingersoll CD. Quadriceps activation following knee injuries: A systematic review. J Athl Train 2010;45:87-97.

45. Park SH, Silva M. Neuromuscular electrical stimulation enhances fracture healing: Results of an animal model. J Orthop Res 2004;22:382-387.

46. Toth MJ, Tourville TW, Voigt TB, Choquette RH, Anair BM, Falcone MJ, et al. Utility of neuromuscular electrical stimulation to preserve quadriceps muscle fiber size and contractility after anterior cruciate ligament injuries and reconstruction: A randomized, shamcontrolled, blinded trial. Am J Sports Med 2020;48: 2429-2437.

47. Escamilla RF, Macleod TD, Wilk KE, Paulos L, Andrews JR. Anterior cruciate ligament strain and tensile forces for weight-bearing and non-weight-bearing exercises: A guide to exercise selection. J Orthop Sports Phys Ther 2012:42:208-220.

48. Hughes L, Paton B, Rosenblatt B, Gissane C, Patterson SD. Blood flow restriction training in clinical musculoskeletal rehabilitation: A systematic review and meta-analysis. Br J Sports Med 2017;51:1003-1011.

49. Woodmass JM, Romatowski NP, Esposito JG, Mohtadi NG, Longino PD. A systematic review of peroneal nerve palsy and recovery following traumatic knee dislocation. Knee Surg Sports Traumatol Arthrosc 2015;23: 2992-3002.

50. Sanders TL, Johnson NR, Levy NM, Cole PA Jr, Krych AJ, Stuart M, et al. Effect of vascular injury on functional outcome in knees with multi-ligament injury: A matched-cohort analysis. J Bone Joint Surg Am 2017;99: 1565-1571.

51. Worley JR, Brimmo O, Nuelle CW, Cook JL, Stannard JP. Incidence of concurrent peroneal nerve injury in multiligament knee injuries and outcomes after knee reconstruction. J Knee Surg 2019;32:560-564.

52. Meunier A, Odensten M, Good L. Long-term results after primary repair or non-surgical treatment of anterior cruciate ligament rupture: A randomized study with a 15-year follow-up. Scand J Med Sci Sports 2007;17: 230-237.

53. Arhos EK, Thoma LM, Grindem H, Logerstedt D, Risberg MA, Snyder-Mackler L. Association of quadriceps strength symmetry and surgical status with clinical osteoarthritis 5 years after anterior cruciate ligament rupture [published online October 7, 2020]. Arthritis Care Res (Hoboken). doi: 10.1002/acr.24479.

54. Toutoungi DE, Lu TW, Leardini A, Catani F, O'Connor JJ. Cruciate ligament forces in the human knee during rehabilitation exercises. Clin Biomech (Bristol, Avon) 2000;15:176-187.

55. Shelburne KB, Pandy MG. Determinants of cruciateligament loading during rehabilitation exercise. Clin Biomech (Bristol, Avon) 1998;13:403-413. 
56. Guruhan S, Kafa N, Ecemis ZB, Guzel NA. Muscle activation differences during eccentric hamstring exercises. Sports Health 2021;13:181-186.

57. Muddle TWD, Colquhoun RJ, Magrini MA, Luera MJ, DeFreitas JM, Jenkins NDM. Effects of fatiguing, submaximal high- versus low-torque isometric exercise on motor unit recruitment and firing behavior. Physiol Rep 2018;6:e13675.

58. Lim HY, Wong SH. Effects of isometric, eccentric, or heavy slow resistance exercises on pain and function in individuals with patellar tendinopathy: A systematic review. Physiother Res Int 2018;23:e1721.

59. Hughes L, Patterson SD. The effect of blood flow restriction exercise on exercise-induced hypoalgesia and endogenous opioid and endocannabinoid mechanisms of pain modulation. J Appl Physiol (1985) 2020;128: 914-924.

60. Hellebrandt FA. Application of the overload principle to muscle training in man. Am J Phys Med 1958;37:278-283.

61. Helms ER, Cronin J, Storey A, Zourdos MC. Application of the repetitions in reserve-based rating of perceived exertion scale for resistance training. Strength Cond J 2016;38:42-49.

62. Larsen S, Kristiansen E, van den Tillaar R. Effects of subjective and objective autoregulation methods for intensity and volume on enhancing maximal strength during resistance-training interventions: A systematic review. PeerJ 2021;9:e10663.

63. Kiely J. Periodization paradigms in the 21st century: Evidence-led or tradition-driven? Int J Sports Physiol Perform 2012;7:242-250.

64. Morton RW, Sonne MW, Farias Zuniga A, Mohammad IYZ, Jones A, McGlory C, et al. Muscle fibre activation is unaffected by load and repetition duration when resistance exercise is performed to task failure. J Physiol 2019;597:4601-4613.

65. Dankel SJ, Jessee MB, Mattocks KT, Mouser JG, Counts BR, Buckner SL, et al. Training to fatigue: The answer for standardization when assessing muscle hypertrophy? Sports Med 2017;47:1021-1027.

66. Maupin D, Schram B, Canetti E, Orr R. The relationship between acute: Chronic workload ratios and injury risk in sports: a systematic review. Open Access J Sports Med 2020;11:51-75.

67. Morrison S, Ward P, duManoir GR. Energy system development and load management through the rehabilitation and return to play process. Int J Sports Phys Ther 2017;12:697-710.

68. Angelozzi M, Madama M, Corsica C, et al. Rate of force development as an adjunctive outcome measure for return-to-sport decisions after anterior cruciate ligament reconstruction. J Orthop Sports Phys Ther 2012;42: 772-780.

69. Buckthorpe M, Roi GS. The time has come to incorporate a greater focus on rate of force development training in the sports injury rehabilitation process. Muscles Ligaments Tendons J 2017;7:435-441.

70. Grooms D, Appelbaum G, Onate J. Neuroplasticity following anterior cruciate ligament injury: A framework for visual-motor training approaches in rehabilitation. J Orthop Sports Phys Ther 2015;45:381-393.
71. Gokeler A, Neuhaus D, Benjaminse A, Grooms DR, Baumeister J. Principles of motor learning to support neuroplasticity after ACL injury: Implications for optimizing performance and reducing risk of second ACL injury. Sports Med 2019;49:853-865.

72. Patel AR, Sarkisova N, Smith R, Gupta K, VandenBerg CD. Socioeconomic status impacts outcomes following pediatric anterior cruciate ligament reconstruction. Medicine (Baltimore) 2019;98:e15361.

73. Richter DL, Held MMFG, Laubscher M, et al. Considerations in the management of knee dislocations in the limited resource setting (KD-LRS). Asian J Arthrosc 2020;5:66-72.

74. Li X, Galvin JW, Li C, Agrawal R, Curry EJ. The impact of socioeconomic status on outcomes in orthopaedic surgery. J Bone Joint Surg Am 2020;102:428-444.

75. Iwame T, Matsuura T, Okahisa T, et al. Quadriceps strength to body weight ratio is a significant indicator for initiating jogging after anterior cruciate ligament reconstruction. Knee 2021;28:240-246.

76. Lorenz D, Domzalski S. Criteria-based return to sprinting progression following lower extremity injury. Int J Sports Phys Ther 2020;15:326-332.

77. Taberner M, Allen T, Cohen DD. Progressing rehabilitation after injury: Consider the 'control-chaos continuum. Br J Sports Med 2019;53:1132.

78. Buckthorpe M, Della Villa F, Della Villa S, Roi GS. Onfield rehabilitation part 2: A 5-stage program for the soccer player focused on linear movements, multidirectional movements, soccer-specific skills, soccer-specific movements, and modified practice. J Orthop Sports Phys Ther 2019;49:570-575.

79. Blanch P, Gabbett TJ. Has the athlete trained enough to return to play safely? The acute:chronic workload ratio permits clinicians to quantify a player's risk of subsequent injury. Br J Sports Med 2016;50:471-475.

80. Davies GJ, McCarty E, Provencher M, Manske RC. ACL return to sport guidelines and criteria. Curr Rev Musculoskelet Med 2017;10:307-314.

81. Kyritsis P, Bahr R, Landreau P, Miladi R, Witvrouw E. Likelihood of ACL graft rupture: Not meeting six clinical discharge criteria before return to sport is associated with a four times greater risk of rupture. Br J Sports Med 2016;50:946.

82. Grindem H, Snyder-Mackler L, Moksnes H, Engebretsen L, Risberg MA. Simple decision rules can reduce reinjury risk by $84 \%$ after ACL reconstruction: The Delaware-Oslo ACL cohort study. Br J Sports Med 2016;50:804-808.

83. Abrams GD, Harris JD, Gupta AK, McCormick FM, BushJoseph CA, Verma NN, et al. Functional performance testing after anterior cruciate ligament reconstruction: A systematic review. Orthop J Sports Med 2014;2: 2325967113518305.

84. Sigward SM, Chan MM, Lin PE, Almansouri SY, Pratt KA. Compensatory strategies that reduce knee extensor demand during a bilateral squat change from 3 to 5 months following anterior cruciate ligament reconstruction. J Orthop Sports Phys Ther 2018;48:713-718.

85. Losciale JM, Zdeb RM, Ledbetter L, Reiman MP, Sell TC. The association between passing return-to-sport criteria 
and second anterior cruciate ligament injury risk: A systematic review with meta-analysis. J Orthop Sports Phys Ther 2019;49:43-54.

86. Kuenze C, Hertel J, Saliba S, Diduch DR, Weltman A, Hart JM. Clinical thresholds for quadriceps assessment after anterior cruciate ligament reconstruction. J Sport Rehabil 2015;24:36-46.

87. Saper MG, Fantozzi P, Bompadre V, Racicot M, Schmale GA. Return-to-sport testing after medial patellofemoral ligament reconstruction in adolescent athletes. Orthop J Sports Med 2019;7:2325967119828953.

88. Bolgla LA, Keskula DR. Reliability of lower extremity functional performance tests. J Orthop Sports Phys Ther 1997;26:138-142.

89. Schmitt LC, Paterno MV, Hewett TE. The impact of quadriceps femoris strength asymmetry on functional performance at return to sport following anterior cruciate ligament reconstruction. J Orthop Sports Phys Ther 2012;42:750-759.

90. Paterno MV, Schmitt LC, Ford KR, Rauh MJ, Myer GD, Huang B, et al. Biomechanical measures during landing and postural stability predict second anterior cruciate ligament injury after anterior cruciate ligament reconstruction and return to sport. Am J Sports Med 2010;38:1968-1978.

91. Norouzi S, Esfandiarpour F, Mehdizadeh S, Yousefzadeh NK, Parnianpour M. Lower extremity kinematic analysis in male athletes with unilateral anterior cruciate reconstruction in a jump-landing task and its association with return to sport criteria. BMC Musculoskelet Disord 2019;20:492.

92. Zwolski C, Schmitt LC, Quatman-Yates C, Thomas S, Hewett TE, Paterno MV. The influence of quadriceps strength asymmetry on patient-reported function at time of return to sport after anterior cruciate ligament reconstruction. Am J Sports Med 2015;43:2242-2249.

93. Keays SL, Bullock-Saxton JE, Newcombe P, Keays AC. The relationship between knee strength and functional stability before and after anterior cruciate ligament reconstruction. J Orthop Res 2003;21:231-237.

94. Pietrosimone B, Lepley AS, Harkey MS, et al. Quadriceps strength predicts self-reported function post-ACL reconstruction. Med Sci Sports Exerc 2016;48:1671-1677.

95. Sadeqi M, Klouche S, Bohu Y, Herman S, Lefevre N, Gerometta A. Progression of the psychological ACL-RSI score and return to sport after anterior cruciate ligament reconstruction: A prospective 2-year follow-up study from the French Prospective Anterior Cruciate Ligament Reconstruction Cohort Study (FAST). Orthop J Sports Med 2018;6:2325967118812819.
96. Ardern CL, Taylor NF, Feller JA, Whitehead TS, Webster KE. Psychological responses matter in returning to preinjury level of sport after anterior cruciate ligament reconstruction surgery. Am J Sports Med 2013;41: 1549-1558.

97. Webster KE, Feller JA. Development and validation of a short version of the anterior cruciate ligament return to sport after injury (ACL-RSI) scale. Orthop J Sports Med 2018;6:2325967118763763.

98. Albano TR, Rodrigues CAS, Melo AKP, de Paula PO, Almeida GPL. Clinical decision algorithm associated with return to sport after anterior cruciate ligament reconstruction. J Athl Train 2020;55:691-698.

99. Hanley JM, Anthony CA, DeMik D, et al. Patient-reported outcomes after multiligament knee injury: MCL repair versus reconstruction. Orthop J Sports Med 2017;5: 2325967117694818.

100. Karataglis D, Bisbinas I, Green MA, Learmonth DJ. Functional outcome following reconstruction in chronic multiple ligament deficient knees. Knee Surg Sports Traumatol Arthrosc 2006; 14:843-847.

101. Beischer S, Gustavsson L, Senorski EH, et al. Young athletes who return to sport before 9 months after anterior cruciate ligament reconstruction have a rate of new injury 7 times that of those who delay return. J Orthop Sports Phys Ther 2020;50:83-90.

102. Mai HT, Alvarez AP, Freshman RD, et al. The NFL Orthopaedic Surgery Outcomes Database (NO-SOD): The effect of common orthopaedic procedures on football careers. Am J Sports Med 2016;44:2255-2262.

103. Nagaraj R, Shivanna S. Pattern of multiligament knee injuries and their outcomes in a single stage reconstruction: Experience at a tertiary orthopedic care centre. J Clin Orthop Trauma 2021;15:156-160.

104. Paterno MV, Hewett TE. Biomechanics of multi-ligament knee injuries (MLKI) and effects on gait. $N$ Am J Sports Phys Ther 2008;3:234-241.

105. Scholes CJ, Lynch JT, Ebrahimi M, Fritsch BA, Parker DA. Gait adaptations following multiple-ligament knee reconstruction occur with altered knee kinematics during level walking. Knee Surg Sports Traumatol Arthrosc 2017;25:1489-1499.

106. Neri T, Myat D, Beach A, Parker DA. Multiligament knee injury: Injury patterns, outcomes, and gait analysis. Clin Sports Med 2019;38:235-246.

107. Hart JM, Blanchard BF, Hart JA, Montgomery SC, Schoderbek R, Miller MD. Multiple ligament knee reconstruction clinical follow-up and gait analysis. Knee Surg Sports Traumatol Arthrosc 2009; 17:277-285. 